\title{
Special Issue on Cognitive Load Theory: Editorial
}

\author{
Paul Ginns ${ }^{1} \cdot$ Jimmie Leppink ${ }^{2,3}$
}

Published online: 2 February 2019

(C) The Author(s) 2019

\begin{abstract}
For over three decades, cognitive load theory (CLT) has drawn on models of cognitive architecture-including a working memory whose capacity and duration limits can be substantially reduced when domain-specific schemas are activated from long-term memory - to generate and test instructional design hypotheses. The cognitive load construct refers to the load placed on working memory by a range of cognitive processes, including comprehension, schema construction, schema automation, and problem solving. When working memory is overloaded by the competing demands of these processes, CLT argues, student learning is impaired. Using CLT, researchers have (typically) used experimental methods to test a range of instructional designs that variously target obstructions to learning (e.g., split attention) or develop strategies to circumvent these issues (e.g., worked examples; for summaries of CLT designs, see Kalyuga 2015; Sweller et al. 2011). This Special Issue presents 10 articles, including theoretical reviews, meta-analyses, and intervention studies, that all focus on a unique aspect of advancement of CLT or cognate theories such as Mayer's cognitive theory of multimedia learning (CTML). Drawing in part on ongoing research presented at the 2017 and 2018 International Cognitive Load Theory Conferences, the Special Issue also reflects on the impact of a key review of CLT published in Educational Psychology Review by Sweller et al. (Educational Psychology Review, 10(3), 251-296, 1998), "Cognitive architecture and instructional design." The impact of this review of CLT is clearly seen in citation counts as of 8 January 2019 (1862 citations in Web of Science; 5092 citations in Google Scholar).
\end{abstract}

Keywords Cognitive load theory $\cdot$ Learning $\cdot$ Instruction

Jimmie Leppink

hyj117@hyms.ac.uk

1 University of Sydney, Sydney, Australia

2 University of York, York, UK

3 Maastricht University, Maastricht, the Netherlands 


\section{Special Issue on Cognitive Load Theory: Editorial}

For over three decades, cognitive load theory (CLT) has drawn on models of cognitive architecture - including a working memory whose capacity and duration limits can be substantially reduced when domain-specific schemas are activated from long-term memory-to generate and test instructional design hypotheses. The cognitive load construct refers to the load placed on working memory by a range of cognitive processes, including comprehension, schema construction, schema automation, and problem solving. When working memory is overloaded by the competing demands of these processes, CLT argues, student learning is impaired. Using CLT, researchers have (typically) used experimental methods to test a range of instructional designs that variously target obstructions to learning (e.g., split attention) or develop strategies to circumvent these issues (e.g., worked examples; for summaries of CLT designs, see Kalyuga 2015; Sweller et al. 2011).

This Special Issue presents 11 articles, including theoretical reviews, meta-analyses, and intervention studies, that all focus on a unique aspect of advancement of CLT or cognate theories such as Mayer's cognitive theory of multimedia learning (CTML). Drawing in part on ongoing research presented at the 2017 and 2018 International Cognitive Load Theory Conferences, the Special Issue also reflects on the impact of a key review of CLT published in Educational Psychology Review by Sweller et al. (1998), "Cognitive architecture and instructional design." The impact of this review of CLT is clearly seen in citation counts as of 8 January 2019 (1862 citations in Web of Science; 5092 citations in Google Scholar).

Since publication of this seminal review, further extensive theoretical and empirical work has helped cognitive load theory to develop further. What is the state of affairs 20 years after the 1998 review? In the first review, Sweller et al. (2019) discuss key developments from the past two decades: the introduction of the biologically primary-secondary knowledge distinction based on evolutionary theorizing (Geary 2008), the four-component instructional design (4C/ID) model, the discovery of ten new instructional effects, and the development of new cognitive load measurement instruments. Working memory resource depletion, the bridge between cognitive load theory and self-regulated learning, the role of emotion as well as stress and uncertainty in cognitive load theory, and relations between human movement and cognitive load constitute four key research lines for the time ahead.

In the second review, Sepp et al. (2019) propose a new integrated working memory model that can help us to understand ways on how the human motor system may influence learning and cognition. The central tenet of this new model is a common and finite attentional resource that can be distributed across multiple modalities. This model may help researchers to understand the effects of gestures and other movements on cognitive load. Sepp and colleagues call for an increased use of eye tracking and motion tracking technology in future experiments. Motion tracking may help not only to measure full body movement but also fine hand and finger movements as well, and the latter may shed light on effects of tracing on cognitive load.

In the third review, Feldon et al. (2019) propose an Expectancy-Value-Cost TheoryCognitive Load Theory (EVCT-CLT) model in which motivational beliefs and changes therein can result directly from cognitive load and manipulations thereof. Integrating research traditions from EVCT and CLT may help us to get the best of two worlds. On the one hand, EVCT may provide us with a perspective to better understand the role of motivation and selfregulation in learning and in CLT. On the other hand, much of the research on the links among EVCT constructs has relied on correlational research methodologies, while one of the 
core features of CLT is a tradition of carefully designed randomized controlled experiments. Feldon and colleagues provide suggestions for the design of new experiments on relations between motivation, self-regulation, and cognitive load as well as for the measurement of these constructs.

There have been recurrent calls to expand instructional design theories such as CLT and CTML (e.g., Brünken et al. 2011; Moreno and Mayer 2007) to specify the role of affective factors. In the fourth review, Plass and Kalyuga (2019) consider ways in which scholarship on emotional experiences during learning might inform CLT. Building on the interval theory view of cognitive load presented by Kalyuga and Singh (2016) and drawing scholarship from affective neuroscience, educational psychology, cognitive psychology, and positive psychology, Plass and Kalyuga suggest four distinct ways in which emotions may relate to cognitive load during learning.

The first meta-analysis by Castro-Alonso et al. (2019) reviews experimental studies of learning from static versus dynamic visualizations. Over the past decade, consideration of the distinction between biologically primary and secondary knowledge categories by CLT researchers has provided a novel explanation for mixed results in this field of research. Identifying 46 studies for inclusion, the authors found a small average benefit of dynamic visualizations over static visualizations. Castro and colleagues extend research in this field by focusing on gender as a potential moderator of the overall effect, alongside educational level, learning domain, media compared, and reporting reliability measures. The second metaanalysis by Rey et al. (2019) reviews experimental studies of the segmenting effect, derived from Mayer's (2005) CTML. In common with CLT, CTML carefully considers the operating characteristics of human cognitive architecture in formulating instructional design hypotheses. The segmenting effect occurs when learning is improved as a result of multimedia-based instructions being presented in meaningful, coherent, and learner-paced segments, rather than in a continuous format. Rey and colleagues identified 57 individual studies for inclusion in the meta-analysis, finding that for system-paced instruction, segmentation increased learning time, reduced cognitive load, and improved retention and transfer test performance. Together, these meta-analyses provide important summaries of recent multimedia instructional design research, including boundary conditions that can both inform instructional design practice and guide future research.

Empirical studies in this Special Issue informed by CLT begin with Leppink and PérezFuster's (2019) re-analyses of data from four recently published studies. Each of these studies included repeated measures of self-reported mental effort along with either workload, time on task, or self-rated certainty of correct task performance. In three of the four studies, mental effort was more suitably modeled as a non-linear rather than linear predictor of outcomes. These results provide initial evidence for CLT researchers to consider a range of mental effort curves during a learning phase when repeated measures are used. Beyond promoting a more multivariate approach to understanding the dynamics of learning through the lens of CLT, the study also provides an excellent example of collegial data sharing.

Tang et al. (2019) introduce embodied and grounded cognition to CLT research, remind us why the biologically primary-secondary knowledge distinction is an important part of CLT, and shed light on a potentially important factor involved in extraneous cognitive load: physically moving with an index finger along a poster displaying a cycle such as the water cycle can reduce extraneous cognitive load and result in better learning outcomes. Tang and colleagues call for new experiments to test the hypothesis that larger poster formats will generate larger tracing effects. The rationale behind this hypothesis is that larger formats could 
support larger tracing gestures and hence result in increased working memory capacity across multiple working memory channels.

Leahy and Sweller (2019) present three experiments based on CLT's consideration of the testing effect through the lens of working memory resource depletion (Chen et al. 2018). This line of research represents a marked departure for CLT, which until recently has typically considered prior knowledge in long-term memory as the key source of individual differences in the human cognitive architecture affecting learning (cf. Kalyuga 2007). Based on a complex of results from immediate versus delayed post-tests, each preceded by an assessment of working memory capacity, the authors conclude that the failure to obtain a testing effect using immediate tests may at least be in part due to working memory depletion.

The final intervention study by Likourezos et al. (2019) presents two experiments investigating the impact on learning of variability in instructional task features, in combination with level of instructional guidance in Experiment 1 (worked examples vs. unguided problemsolving) and learner expertise in Experiment 2 (low vs. high). Low variability instructional materials, regardless of level of instructional guidance, enhanced learning in Experiment 1. A disordinal aptitude-treatment interaction was found in Experiment 2, indicating an expertise reversal effect: students with low prior knowledge who solved problems with low variability outperformed those who solved problems with high variability on a subsequent test, but the opposite pattern of results was found for students with higher prior knowledge. These results provide a new example of the moderating effect of expertise in cognitive load theory, while demonstrating the ongoing "cross-pollination" in CLT research as boundary conditions of established CLT effects is demonstrated.

The Special Issue concludes with an interview with CLT's founders. Mavilidi and Zhong (2019) invite John Sweller, Fred Paas, and Jeroen van Merriënboer to reflect on changes to the theory since the publication of Sweller et al. (1998). The interviewees also discuss their current research foci, give their views on ongoing points of contention such as measurement of cognitive load, and provide advice and suggestions for young researchers.

Open Access This article is distributed under the terms of the Creative Commons Attribution 4.0 International License (http://creativecommons.org/licenses/by/4.0/), which permits unrestricted use, distribution, and reproduction in any medium, provided you give appropriate credit to the original author(s) and the source, provide a link to the Creative Commons license, and indicate if changes were made.

\section{References}

Brünken, R., Plass, J. L., \& Moreno, R. (2011). Current issues and open questions in cognitive load research. In J. Plass, R. Moreno, \& R. Brünken (Eds.), Cognitive load theory (pp. 253-272). New York: Cambridge University Press.

Castro-Alonso, J. C., Wong, A., Adesope, O. O., Ayres, P., \& Paas, F. (2019). Gender imbalance in instructional dynamic versus static visualizations: a meta-analysis. Educational Psychology Review, 31, 1-27.

Chen, O., Castro-Alonso, J. C., Paas, F., \& Sweller, J. (2018). Extending cognitive load theory to incorporate working memory resource depletion: evidence from the spacing effect. Educational Psychology Review, 30(2), 483-501. https://doi.org/10.1007/s10648-017-9426-2.

Feldon, D., Callan, G., Juth, S., \& Jeong, S. (2019). Cognitive load as motivational cost. Educational Psychology Review, 31. https://doi.org/10.1007/s10648-019-09464-6.

Geary, D. (2008). An evolutionarily informed education science. Educational Psychologist, 43(4), 179-195. https://doi.org/10.1080/00461520802392133.

Kalyuga, S. (2007). Expertise reversal effect and its implications for learner-tailored instruction. Educational Psychology Review, 19(4), 509-539. https://doi.org/10.1007/s10648-007-9054-3. 
Kalyuga, S. (2015). Instructional guidance: a cognitive load perspective. Charlotte, NC: Information Age Processing.

Kalyuga, S., \& Singh, A. M. (2016). Rethinking the boundaries of cognitive load theory in complex learning. Educational Psychology Review, 28(4), 831-852. https://doi.org/10.1007/s10648-015-9352-0.

Leahy, W., \& Sweller, J. (2019). Cognitive load theory, resource depletion and the delayed testing effect. Educational Psychology Review, 31.

Leppink, J., \& Pérez-Fuster, P. (2019). Mental effort, workload, time on task, and certainty: beyond linear models. Educational Psychology Review, 31. https://doi.org/10.1007/s10648-018-09460-2.

Likourezos, V., Kalyuga, S., \& Sweller, J. (2019). The variability effect: when instructional variability is advantageous. Educational Psychology Review, 31. https://doi.org/10.1007/s10648-019-09462-8.

Mavilidi, M. F., \& Zhong, L. (2019). Exploring the development and research focus of cognitive load theory, as described by its founders: interviewing John Sweller, Fred Paas, and Jeroen van Merriënboer. Educational Psychology Review, 31. https://doi.org/10.1007/s10648-019-09463-7.

Mayer, R. E. (2005). Cognitive theory of multimedia learning. In R. Mayer (Ed.), Cambridge handbook of multimedia learning (pp. 31-48). New York: Cambridge University Press.

Moreno, R., \& Mayer, R. (2007). Interactive multimodal learning environments. Educational Psychology Review, 19(3), 309-326. https://doi.org/10.1007/s10648-007-9047-2.

Plass, J. L., \& Kalyuga, S. (2019). Four ways of considering emotion in cognitive load theory. Educational Psychology Review, 31.

Rey, G. D., Beege, M., Nebel, S., Wirzberger, M., Schmitt, T. H., \& Schneider, S. (2019). A meta-analysis of the segmenting effect. Educational Psychology Review, 31. https://doi.org/10.1007/s10648-018-9456-4.

Sepp, S., Howard, S., Tindall-Ford, S., Agostinho, S. \& Paas, F. (2019). Cognitive load theory and human movement: Towards an integrated model of working memory. Educational Psychology Review, 31. https://doi.org/10.1007/s10648-019-09461-9.

Sweller, J., van Merriënboer, J. J. G., \& Paas, F. (1998). Cognitive architecture and instructional design. Educational Psychology Review, 10(3), 251-296. https://doi.org/10.1023/A:1022193728205.

Sweller, J., Ayres, P., \& Kalyuga, S. (2011). Cognitive load theory. New York, NY: Springer.

Sweller, J., van Merriënboer, J. J. G., \& Paas, F. (2019). Cognitive architecture and instructional design: 20 years later. Educational Psychology Review, 31. https://doi.org/10.1007/s10648-019-09465-5.

Tang, M., Ginns, P., \& Jacobson, M. J. (2019). Tracing enhances recall and transfer of knowledge of the water cycle. Educational Psychology Review, 31. https://doi.org/10.1007/s10648-019-09466-4.

Publisher's Note Springer Nature remains neutral with regard to jurisdictional claims in published maps and institutional affiliations. 